Mr Zvonko Radosavljević, dipl. inž Vojnotehnički institut Beograd

\section{ANALIZA PRIMENE IMM ALGORITMA ZA PRAĆENJE MANEVRIŚUĆIH CILJEVA}

Rezime:

U radu je analizirana primena IMM algoritma sa tri modela Kalmanovih filtara, za praćenje cilja pomoću osmatračkog radara. Prvi Kalmanov filtar podešen je da prati ciljeve koji se kreću po pravolinijskoj trajektoriji bez ubrzanja, drugi prati ciljeve koji se kreću ubrzano $i$ vrše blag manevar, a treći je namenjen za praćenje ciljeva koji se kreću ubrzano $i$ vrše oštar manevar. Dat je opis algoritma kao i vrednosti odgovarajućih parametara i matrica prelaza za Kalmanove filtre, kao i uporedna analiza algoritma u odnosu na standardan Kalmanov filtar šestog reda. Prikazani rezultati srednje kvadratne greške praćenja po x $i$ y koordinati pokazuju opravdanost izbora predložene metode praćenja.

Ključne reči: praćenje manevrišućih ciljeva, teorija estimacije, Kalmanov filtar.

\title{
ANALYSIS OF IMM ALGORITHM FOR MANOEUVRING TARGET TRACKING
}

Summary:

This paper considers comparative analysis the problem of manoeuvring target tracking to IMM algorithm with 3 standard Kalman filters and same standard Kalman filter 6. order, using data from TWS radar. The first Kalman filter from IMM algorithms is tuned for tracking of target moving along the rectilinear trajectory without acceleration, the second tracks the targets with acceleration and gentle maneuver, and the third Kalman filter tracks the target with acceleration and sharp maneuver. The mathematical model of algorithm and values of appropriate parameters and Kalman filter matrices, are presented. The results of RMSE of tracking in $x$ and $y$ coordinates, show the validity of the proposed method.

Key words: target tracking, theory of estimation, Kalman filter.

\section{Uvod}

Za praćenje manevrišućih ciljeva pomoću osmatračkih TWS (Track While Scan) radara, koji hipotetički mogu da se kreću po trajektorijama sa velikim mogućnostima manevra, počev od pravolinijskog kretanja do ubrzanog kretanja sa oštrim manevrom, koristi se IMM (Interactive Multipl Model) algoritam. Ovaj algoritam omogućava praćenje ciljeva koji se kreću na tri načina: pravolinijski bez ubrzanja, ubrzano sa blagim manevrom i ubrzano sa oštrim manevrom, interaktivno poboljšavajući karakteristike praćenja u zavisnosti od greške koju čini svaki od filtara.

Za razumevanje rada ovog algoritma neophodno je poznavati pojam ,prozora““. Pod pojmom prozora podrazumeva se odgovarajući kružni, eliptički ili pravougaoni prostor oko predviđenog položaja traga iz prethodnog skena. Sva 
merenja koja se nalaze unutar prozora razmatraju se u procesu ažuriranja traga.

Osnova IMM algoritma predstavlja paralelno korišćenje filtara za različite modele kretanja cilja. Karakteriše ga rekurzivnost, modularnost i konstantni zahtevi u pogledu računskih operacija tokom jednog ciklusa izvršavanja.

Dvodimenzionalni osmatrački radari daju podatke u polarnim koordinatama, a praćenje se vrši u Dekartovom koordinatnom sistemu. Zato je potrebno rešiti problem usklađivanja koordinatnih sistema. Prelazak iz sfernog u Dekartov koordinatni sistem uzrok je međusobne korelisanosti koordinata. U slučaju opisanom u radu pojavljuje se međusobna korelisanost koordinata. Zbog toga je potrebno pronaći matematička očekivanja složene funkcije dve međusobno korelisane promenljive preko odgovarajućih Jakobijan matrica. U literaturi [1] prikazan je model proračuna parametara praćenja manevrišućih ciljeva, pri čemu se model kretanja cilja može aproksimirati modelima kretanja u slučaju prikazanom u ovom radu.

\section{Opis IMM algoritma}

Osnovu predloženog algoritma čini N - Kalmanovih filtra, po jedan za svaki od očekivanih modela kretanja. U predloženom modelu za simulaciju usvojena je konfiguracija sa tri Kalmanova filtra koja se $u$ literaturi pokazala optimalnom za primenu u radarskom praćenju vazdušnih manevrišućih ciljeva. Na osnovu literature [2, 3 i 4] obrađena je problematika određivanja efikasnosti praćenja cilja odabranom metodom, $\mathrm{i}$ dati su modeli proračuna kovarijacione matrice šuma merenja $R$ i procesa $Q$. U opštem slučaju, ove matrice su nestacionarne $u$ vre- menu. Problem određivanja elemenata matrice R svodi se na problem poznavanja parametara senzora, dok je definisanje elemenata matrice $Q$ povezano sa poznavanjem dinamike kretanja cilja.

U literaturi [4 i 5] dat je opis IMM algoritma. Polazi se od jednačina za stacionarni diskretni linearni sistem sa poznatim parametrima [4]:

$$
\begin{aligned}
& x_{t+1}=F x_{t}+Q_{t} \\
& y_{t}=H_{t} x_{t}+R_{t}
\end{aligned}
$$

gde je:

$x_{t+1}$ - vektor stanja sistema $\mathrm{u}$ trenutku $t+1$,

$y_{t}$ - vektor merenja u trenutku $t$,

$F$ - matrica prelaza stanja,

$H_{t}$ - matrica merenja u trenutku $t+1$.

Posle inicijalizacije parametara i matrice prelaza iz pojedinih hipoteza izračunavaju se kovarijacione matrice šuma procesa i merenja i uslovne Bajesove verovatnoće. Ako je za $n$-dimenzioni slučajni vektor gausovski raspodeljen, tada je združena funkcija gustine verovatnoće u trenutku $t z$ a $j$-ti model filtra data na sledeći način [4]:

$$
\begin{aligned}
& \Lambda_{t}(j)=\frac{1}{\left[(2 \pi)^{n} \operatorname{det}\left(S_{t}^{(j)}\right)\right]^{1 / 2}} \exp \\
& {\left[-\frac{1}{2}\left(r_{t}^{(j)}\right)^{T}\left(S_{t}^{(j)}\right)^{-1} r_{t}(j)\right]}
\end{aligned}
$$

pri čemu su reziduali u trenutku $t$ za $j$-ti model filtra $r_{t}^{(j)}$ :

$$
r_{t}^{(j)}=y_{t}-H \hat{x}_{t \mid t-1}^{(j), 0}
$$


odnosno kovarijaciona matrica reziduala:

$S_{t}^{(j)}=H_{t} P_{t-1} H_{t}^{T}+R_{t}$

koja se izračunava kao greška estimacije budućih stanja kretanja cilja

gde je:

$R_{t}$ - matrica šuma merenja u trenutku t,

$P_{t-1}$ - kovarijaciona matrica šuma merenja u trenutku $t-1$.

IMM algoritam se opisuje u nekoliko koraka [8].

Prvi korak: ciklus počinje izračunavanjem združenih verovatnoća $\mu_{t-1}(i, j)$, korišćenjem uslovne verovatnoće da model $M^{(i)}$ u trenutku $t-1$ pređe u model $M^{(j)}$ u trenutku $t$,

$\mu_{t-1}(i, j)=\frac{p(i, j) \mu_{t-1}(i)}{\bar{c}^{(j)}} i, j=1, \ldots, N$

pri čemu je:

$$
\bar{c}^{(j)}=\sum_{i=1}^{N} p(i, j) \mu_{t-1}^{(i)} \quad j=1, \ldots, N
$$

Drugi korak: kombinovanjem inicijalnih združenih uslova stanja i kovarijacione matrice (sa indeksom 0) za svaki od $j=1, \ldots, N$ filtara, dobija se:

$$
\begin{aligned}
& \hat{x}_{t-1}^{(j), 0}=\sum_{i=1}^{N} \hat{x}_{t-1}^{(i)} \mu_{t-1}(i, j) \\
& P_{t-1}^{(j), 0}=\sum_{i=1}^{N} \mu_{t-1}^{(i, j)} \\
& {\left[P_{t-1}^{(i)}+\left(\hat{x}_{t-1}^{(i)}-\hat{x}_{t-1}^{(j), 0}\right)\left(\hat{x}_{t-1}^{(i)}-\hat{x}_{t-1}^{(j), 0}\right)^{\prime}\right]}
\end{aligned}
$$

Treći korak: izračunavanje združenih gustina verovatnoća za $j=1, \ldots, N$ filtara:

$$
\begin{aligned}
& \Lambda_{t}(j)=\frac{1}{\left[(2 \pi)^{n} \operatorname{det}\left(S_{t}^{(j)}\right)\right]^{1 / 2}} \exp \\
& {\left[-\frac{1}{2}\left(r_{t}^{(j)}\right)^{T}\left(S_{t}^{(j)}\right)^{-1} r_{t}(j)\right]}
\end{aligned}
$$

gde je:

- rezidual,

$r_{t}^{(j)}=y_{t}-H \hat{x}_{t \mid t-1}^{(j), 0}$

- $n$ dimenzija merenja,

- $S_{t}^{(j)}$ matrica kovarijanse sekvence inovacija u filtru sa modelom $M_{j}$.

Četvrti korak: ažuriranje težinskih koeficijenata:

$\mu_{t}^{(j)}=\frac{1}{c} \Lambda_{t}^{(j)} \bar{c}^{(j)}$

pri čemu je:

$c=\sum_{j=1}^{N} \Lambda_{t}^{(j)} \bar{c}^{(j)}$

Peti korak: završni korak predstavlja ponovno kombinovanje estimacija i kovarijacionih matrica, ali sa ažuriranim težinskim koeficijentima:

$$
\begin{aligned}
& \hat{x}_{t}=\sum_{j=1}^{N} \hat{x}_{t}^{(j)} \mu_{t}^{(j)} \\
& P_{t}=\sum_{j=1}^{N} \mu_{t}^{(j)}\left[P_{t}^{(j)}+\left(\hat{x}_{t}^{(j)}-\hat{x}_{t}\right)\left(\hat{x}_{t}^{(j)}-\hat{x}_{t}\right)\right]
\end{aligned}
$$




\section{Definisanje parametara i matrica IMM algoritma}

Prema prethodnom opisu, formiraju se tri Kalmanova filtra, saglasno odabiru tri hipoteze o kretanja cilja. U ovom radu to su hipoteze za tri najčešća modela kretanja: ravnomerno pravolinijsko kretanje bez ubrzanja, ubrzano kretanje cilja sa blagim manevrom i ubrzano kretanje cilja sa oštrim manevrom. Zatim se definišu matematički modeli za tri vrste kretanja i formiraju ulazne procene. Matrice prelaza za pomenute hipotetičke Kalmanove filtre za IMM algoritam date su pomoću izraza (16) i (17) [1]:

$$
\begin{aligned}
& F_{1}=\left[\begin{array}{cccccc}
1 & T & 0 & 0 & 0 & 0 \\
0 & 1 & 0 & 0 & 0 & 0 \\
0 & 0 & 0 & 0 & 0 & 0 \\
0 & 0 & 0 & 1 & T & 0 \\
0 & 0 & 0 & 0 & 1 & 0 \\
0 & 0 & 0 & 0 & 0 & 0
\end{array}\right] \\
& F_{2}=F_{3}=\left[\begin{array}{cccccc}
1 & T & T^{2} / 2 & 0 & 0 & 0 \\
0 & 1 & T & 0 & 0 & 0 \\
0 & 0 & 1 & 0 & 0 & 0 \\
0 & 0 & 0 & 1 & T & T^{2} / 2 \\
0 & 0 & 0 & 0 & 1 & T \\
0 & 0 & 0 & 0 & 0 & 1
\end{array}\right]
\end{aligned}
$$

gde je $T$ perioda uzimanja opservacija.

U postupku kreiranja IMM algoritma, važnu ulogu ima izbor težinskih koeficijenata uz parametre koji se ažuriraju u svakoj periodi okretanja antene radara. Matrica prelaza stanja spregnuta je sa modelom kretanja cilja, i nepromenljiva je tokom rada algoritma.
Matrica $M_{i}$ zavisi od uticaja okoline na senzor i parametara senzora, odnosno, radara kojim se vrši praćenje. U slučaju TWS radara ova matrica će imati sledeći oblik [7]:

$$
M_{i}=\left[\begin{array}{lll}
p_{11} & p_{12} & p_{13} \\
p_{21} & p_{22} & p_{23} \\
p_{31} & p_{32} & p_{33}
\end{array}\right]=\left[\begin{array}{ccc}
0,7 & 0,2 & 0,1 \\
0 & 0,8 & 0,2 \\
0,2 & 0,2 & 0,6
\end{array}\right]
$$

Smanjenje periode skeniranja radara dovodi do povećanja koeficijenata na dijagonali i smanjenja koeficijenata van dijagonale.

U odnosu na izbor koordinatnog sistema postoje dva tipa Kalmanovih filtara - standardni i prošireni. Ukoliko su podaci sa senzora dati u Dekartovim pravouglim koordinatama $(x, y)$, koristi se standardni Kalmanov filtar. U slučaju praćenja pomoću osmatračkog radara sa kojeg stižu podaci o azimutu i rastojanju, koriste se jednačine proširenog Kalmanovog filtra. Tada kovarijaciona matrica šuma merenja $\mathrm{R}$ ima dimenziju $2 \times 2$, i izračunava se preko odgovarajućih Jakobijana, kako je prethodno opisano, na osnovu [2] i [4] na sledeći način:

$$
J_{12 t}=\left[\begin{array}{cc}
\cos \theta_{t} & -\sin \theta_{t} \\
\sin \theta_{t} & \cos \theta_{t}
\end{array}\right]
$$

$$
\begin{aligned}
& R_{o}=\left[\begin{array}{cc}
\sigma_{r}^{2} & 0 \\
0 & \sigma_{\theta}^{2}
\end{array}\right] \\
& R_{t}=J_{12 t} R_{o} J_{12 t}{ }^{T}
\end{aligned}
$$

gde je:

$\theta$ - azimut, 
$\sigma_{r}$ - standardna devijacija po daljini,

$\sigma_{\theta}$ - standardna devijacija po azimutu [4].

Treba uočiti da se kod proširenog Kalmanovog filtra (EKF - Extended Kalman Filter) matrica $R_{o}$ ažurira u svakoj sekvenci. Na sličan način, na osnovu [1] i [8], kao primer data je kovarijaciona matrica šuma procesa, Q, za Kalmanov filtar definisan preko ubrzanja:

$Q_{0}=\left[\begin{array}{ccc}0 & 0 & 0 \\ 0 & 0 & 0 \\ 0 & 0 & \delta_{a}^{2}\end{array}\right]$

$Q=F Q_{0} F^{T}=\left[\begin{array}{ccc}1 & T & T^{2} / 2 \\ 0 & 1 & T \\ 0 & 0 & 1\end{array}\right]$

$\left[\begin{array}{lll}0 & 0 & 0 \\ 0 & 0 & 0 \\ 0 & 0 & \delta_{a}^{2}\end{array}\right]\left[\begin{array}{ccc}1 & 0 & 0 \\ T & 1 & 0 \\ T^{2} / 2 & T & 1\end{array}\right]$

pri čemu su koeficijenti neodređenosti za sve tri vrste kretanja $\delta_{x}^{2}, \delta_{v}^{2}$ i $\delta_{a}^{2}$ respektivno 0,$005 ; 0,008$ i 0,04 [1].

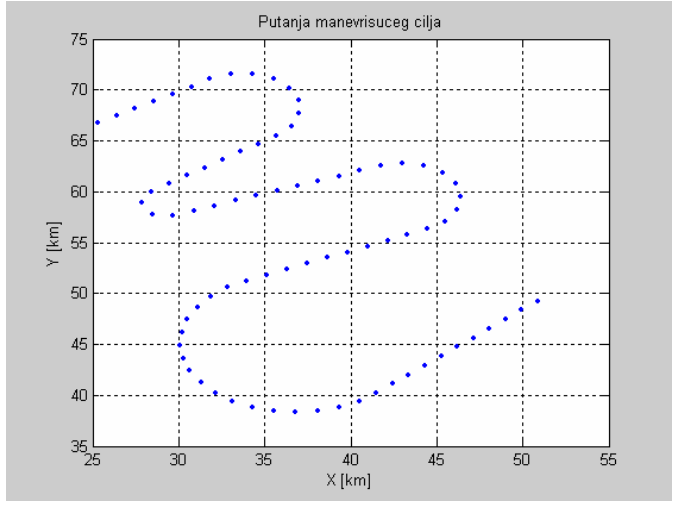

Sl. 1 - Prikaz putanje praćenja cilja

U predloženoj primeni, s obzirom na to da su podaci dati u dvodimenzionalnim Dekartovim koordinatama, koristi se standardni Kalmanov filtar.

\section{Rezultati simulacije}

Simulacija sprovedena radi komparativne analize predloženog algoritma $\mathrm{i}$ standardnog Kalmanovog filtra šestog reda urađena je za dva slučaja: bez uticaja šuma i u prisustvu šuma. Cilj se kreće brzinom od $260 \mathrm{~m} / \mathrm{s}$, vršeći naizmenično četiri vrste manevra sa opterećenjima $g$,

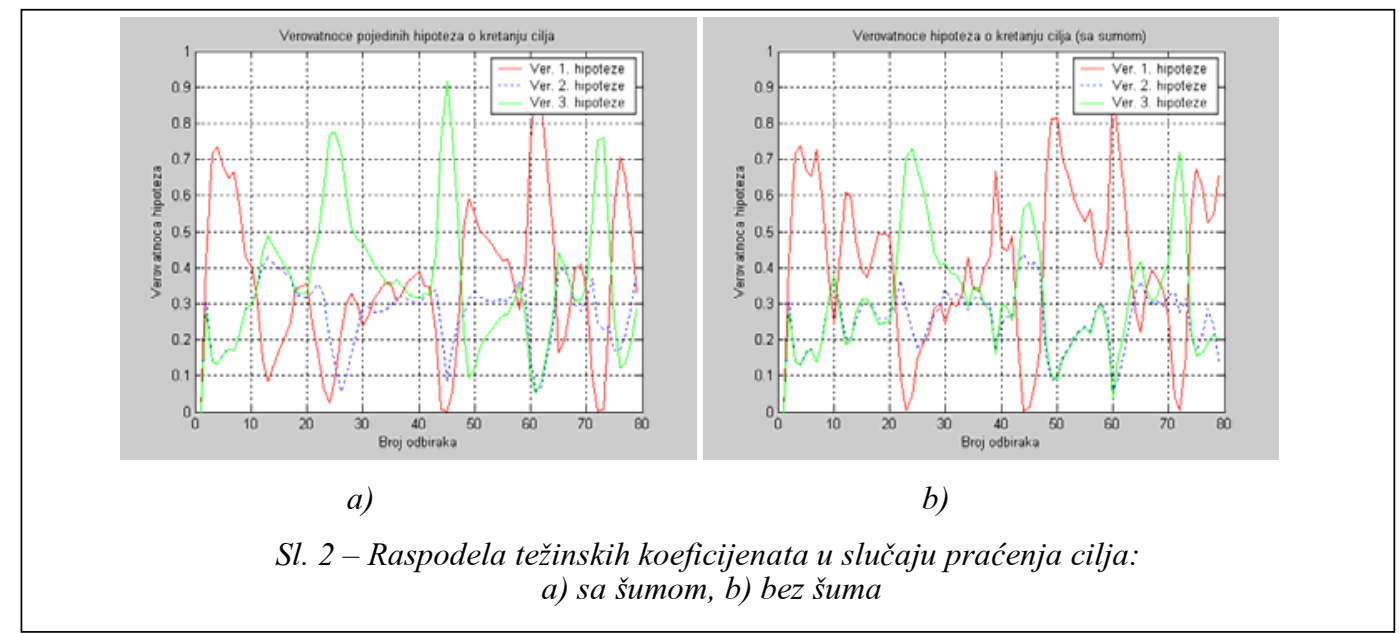




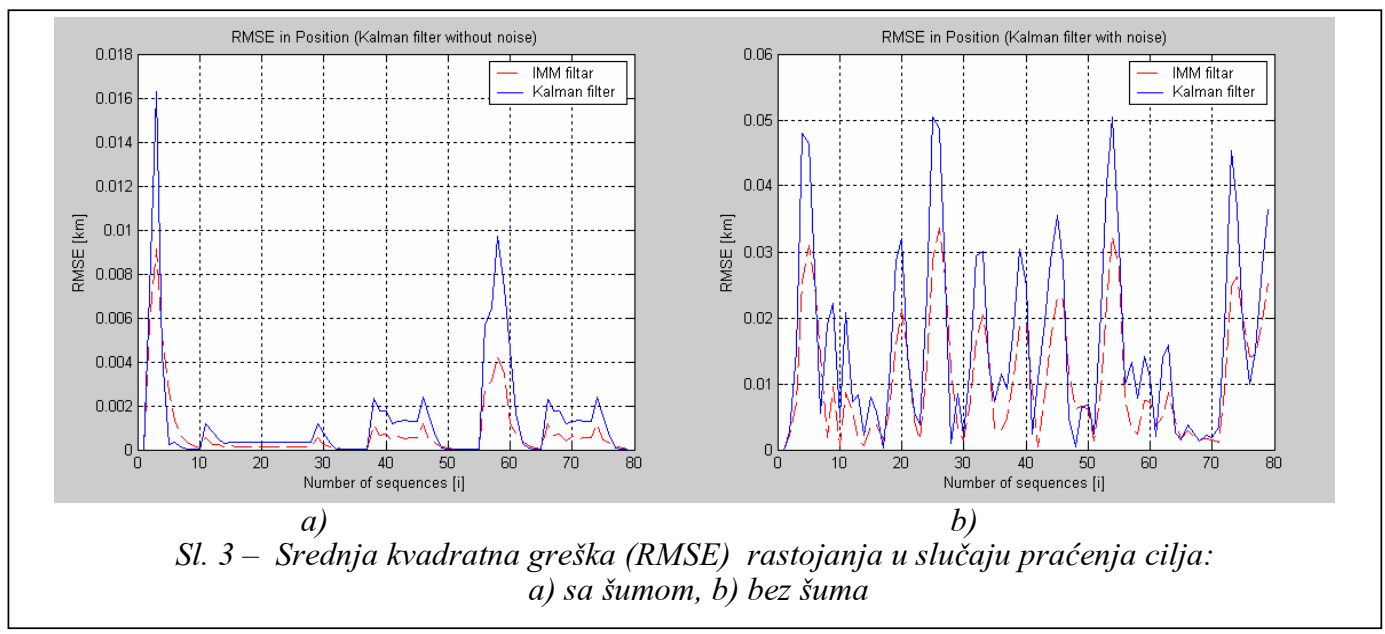

$2 \mathrm{~g}$, $4 \mathrm{~g}$ i $2 \mathrm{~g}$, koji se pojavljuju u intervalima između 10-28, 37-45, 55-58 i 65-73 skena respektivno, u trajanju od 78 skenova [11], sa periodom od $\mathrm{T}=5 \mathrm{~s}$. Funkciji radijusa dodat je šum u iznosu $1 \%$ od aktuelne vrednosti rastojanja, kreiran pomoću generatora slučajnih brojeva sa normalnom raspodelom, čija je srednja vrednost nula, a standardna devijacija 1.

$\mathrm{Na}$ slici $2 \mathrm{a}$ i $2 \mathrm{~b}$ prikazana je raspodela težinskih koeficijenata pojedinih hipoteza za slučaj dve simulacione putanje. $\mathrm{Na}$ njima se mogu uočiti oštri prelazi težinskih koeficijenata $u$ trenucima kada cilj menja vrstu manevra.

Rezultati simulacije predstavljeni su srednjom kvadratnom greškom (RMSE Root Mean Squer Error) praćenja po $x$ i $y$ koordinatama, koja je dobijena na osnovu simulacije Monte Karlo u 70 tačaka [8], i prikazani na slikama 3a i $3 b$.

Radi kvantitativnog određivanja smanjenja greške praćenja prikazan je komparativni grafikon srednje kvadratne greške po rastojanju, u slučaju predloženog IMM algoritma i Kalmanovog filtra. Pored toga, povećanje greške $u$ intervalima izvođenja manevra potvrđuje dobru detekciju i daje mogućnost za klasifikaciju manevra [11], odnosno za klasifikaciju vojnih i civilnih vazduhoplova.

$\mathrm{U}$ tabeli su data izmerena vremena trajanja simulacija koje su rađene u programskom paketu MATLAB 6.5, na računaru P III koji radi na frekvenciji procesora $1200 \mathrm{MHz}$ u slučaju oba komparativna algoritma. Ovi rezultati potvrđuju potrebu za dužim vremenom procesiranja kod IMM algoritma.

Izmerena vremena trajanja simulacije

\begin{tabular}{|l|l|}
\hline Testirana metoda & Vreme (s) \\
\hline Kalmanov filtar & 70,6 \\
\hline IMM filtar & 137,1 \\
\hline
\end{tabular}

\section{Zaključak}

$\mathrm{U}$ radu je prikazana komparativna analiza primene IMM algoritma sa tri modela filtra za osmatrački radar sa periodom okretanja antene od pet sekundi, u odnosu na standardni Kalmanov filtar šestog reda. Prednost predložene metode za estimaciju stanja ogleda se u mogućnosti rekurzivnog uzimanja procene stanja sva tri Kalmanova filtra i izbor filtra koji za posmatrani manevar daje najbolje rezultate. 
Dokazano je kvantitativno poboljšanje praćenja u odnosu na standardni Kalmanov filtar preko srednje kvadratne greške pozicije po obe koordinate.

Analiziran je scenario kretanja jednog cilja bez uticaja šuma i u prisustvu generisanog šuma. Parametri senzora kojim se prati cilj imaju veliki uticaj na koeficijente IMM algoritma (npr. kovarijacionih matrica šuma merenja), a dobijeni razultati potvrđuju pravilan izbor ovih parametara.

Pored toga, potrebno je napomenuti da interaktivnost predložene metode, koja se ogleda u ažuriranju težinskih koeficijenata i kovarijacione matrice greške predikcije u svakoj sekvenci, čine ovu metodu manje osetljivom na izbor početnih parametara.

Osnovni nedostatak ove metode su složena matematička izračunavanja koja angažuju veće računarske kapacitete $u$ odnosu na standardni Kalmanov filtar, tako da je opravdano korišćenje samo u slučajevima praćenja ciljeva sa širokom paletom manevra. Problem se znatno usložava uvođenjem klatera [10], pa se uvodi pojam konstante manevra. Ova problematika je interesantna za buduća istraživanja iz ove oblasti.

Literatura:

[1] Eiserloh, P. P.: An Introduction to Kalman Filters and Applications, Electronic Combat Range, Naval Air Warfare Centar, China Lake, CA, USA, January 2002.

[2] Dikić, G.: Izbor koordinatnih sistema za praćenje ciljeva u multisenzorskom okruženju, Vojnotehnički glasnik, Beo$\operatorname{grad}, 3 / 2002$.

[3] Đurović Z.; Kovačević, B.; Stanković, S.: Praćenje Više Pokretnih Ciljeva Pomoću Osmatračkog Radara, Naučni Tehnički Pregled, Vol. XLI, 1991, br. 7-8.

[4] Kovačevic, B.; Đurović, Z.: Fundamentals of Stochastic Signals, Systems and Estimation Theory with Worked Examples, Academic Mind, Beograd 1999.

[5] Li, X., Bar Shalom, Y.: Design of Interacting Multiple Model Algorithm for Air Traffic Control Tracking, IEEE Transactions on Control Systems Technology, 186-194, September 1993.

[6] Blackman, S.: Multiple-Target Tracking with Radar Applications, Artech House, Dedham 1986.

[7] Wang, X. Challa, S.: Augmented State IMM-PDA for OOSM Solution to Maneuvering Target Tracking in Clutter, IEEE 2003, 479-485.

[8] Karlsson, R.: Simulation Based Methods For Target Tracking, Linkoping Studies in Science and Technology, Thesis No. 930 Department of Electrical Engineering, Linkoping 2002.

[9] Simeonova, I.; Semerdjiev T.: Specific Features of IMM Tracking Filter Design, Information and Security Vol. 9, 2002, pp. 154-165.

[10] Bar-Shalom, Y.: Multitarget multisensor tracking: Advanced applications (Norwood, MA, Artech House, 1990).

[11] Angelova, D.; Mihaylova, L.: Sequential Monte Carlo Algorthms for Joint Target Tracking and Classification Using Kinematic Radar Information. 


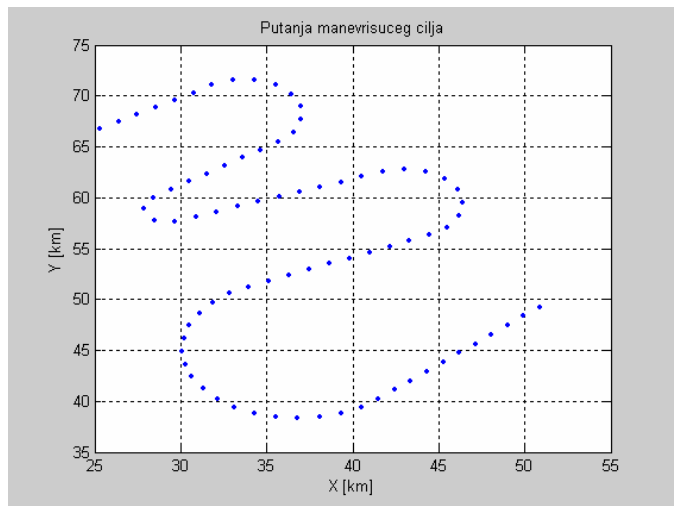

Sl. 1 - Prikaz putanje praćenja cilja

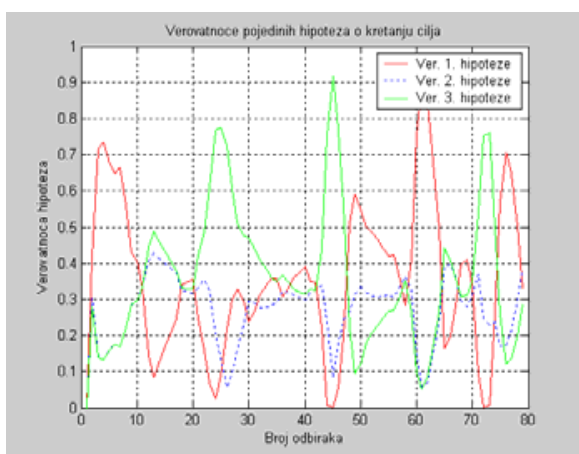

a)

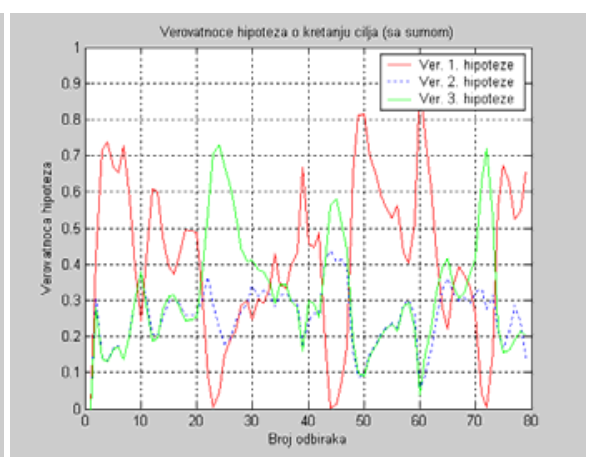

b)

Sl. 2 - Raspodela težinskih koeficijenata u slučaju praćenja cilja: a) sa šumom, b) bez šuma

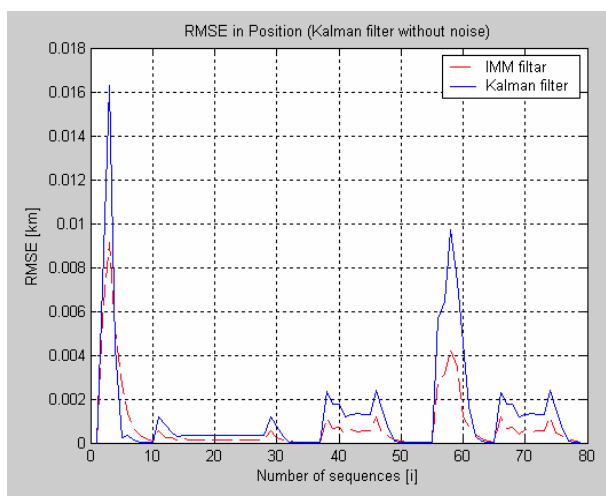

a)

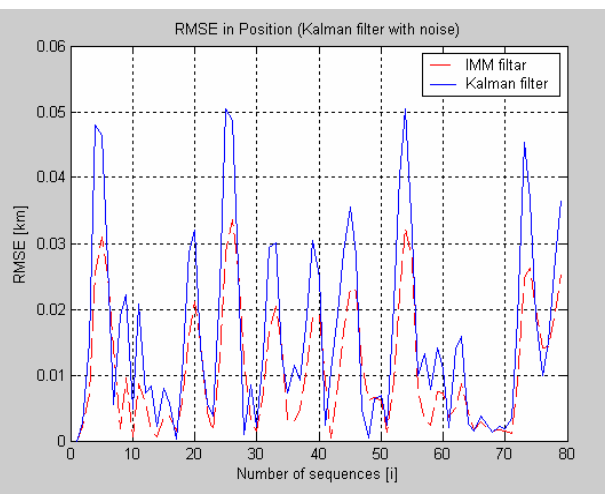

b)

Sl. 3- Srednja kvadratna greška (RMSE) rastojanja u slučaju praćenja cilja: a) sa šumom b) bez šuma 